Senator S. A., Koneva N. V. \& SAXonov S.V. 2009. Critical flora of the Volga river basin: 1. Notes on some species of Samara oblast flora. Institute of ecology of Volga river basin, Russian Academy of Sciences. - Togliatti 11(1-2): 109-125.

SEREGIN A. 2012. Flora of Vladimir Oblast, Russia: checklist and atlas. s. 620. Grif i K., Tula.

Suslova T. A., Czhobadze A. B., Philippov D. A., Shiryaeva O. S. \& Levashov A. N. 2013. The second edition of Red Data Book of the Vologda Region: revisions in lists of protected and biological control required species of plants and fungi. - Fitoraznoobrazie Vostochnoy Evropy 7(3): 93-104.

Tuganaev V. V. (red.). 2001. Red List of the Udmurt Republic. Vascular plants, lichens and mushrooms. s. 290. Udmurtskiy Universitet, Izhevsk.

Red Data Book of Khanty-Mansiysk autonomous county - Ugra. Animals, plants, fungi. 2nd ed. Yekaterinburg: Publishing House «Basko», 2013. 460.

VAsin A. M. (red). 2003. Red Book of the Khanty-Mansiysk Autonomous Okrug: animals, plants, fungi. s. 376. Pakrus, Ekaterinburg.

VEREY M. 2017. Teoretyczna analiza i praktyczne konsekwencje przyjęcia modelowej siatki ATPOL jako odwzorowania stożkowego definiującego konwersję współrzędnych płaskich na elipsoidę WGS 84. - Fragmenta Floristica et Geobotanica Polonica 24(2): 469-488.

ZAJĄC M. \& ZAJĄC A. 2009. Elementy geograficzne rodzimej flory Polski. s. 94. Nakładem Pracowni Chorologii Komputerowej Instytutu Botaniki Uniwersytetu Jagiellońskiego, Kraków.

Karol Torzewski (autor korespondencyjny), Katedra Ekologii, Biogeochemii i Ochrony Środowiska, Uniwersytet Wroctawski, ul. Kanonia 6/8, 50-328 Wroctaw, Polska; e-mail: karol. torzewski@uwr.edu.pl

Anna OtręBA, Kampinoski Park Narodowy, Gospodarstwo Szkótkarskie, ul. Polna 37, 05-084 Leszno, Polska; e-mail: aotreba@kampinoski-pn.gov.pl

Anna KęBeowska, Kampinoski Park Narodowy, Zespót ds. Nauki i Monitoringu Przyrody, ul. Tetmajera 38,05-080 Izabelin,Polska; e-mail: akeblowska@kampinoski-pn.gov.pl

Wptynęto: 09.07.2019 r.; przyjęto do druku: 30.12.2020 r.

DOI: https://doi.org/10.35535/ffgp-2020-0042

\title{
Stellaria pallida (Caryophyllaceae) - nowe znalezisko dla flory Krakowa i skrajnie wschodnie współczesne stanowisko w Polsce
}

Stellaria pallida (Dumort.) Crép., gwiazdnica blada, (Alsine pallida Dumort.; w literaturze (np. MireK i in. 2002) używana też nieważna kombinacja S. pallida (Dumort.) Piré, nom. inval.; LSID: urn:Isid:ipni.org:names:983852-1) jest jednym z gatunków grupy $S$. media (diploidalnym, 2n=22, w odróżnieniu od S. media (L.) Vill. s. str. o 2n=40-44). Od pewnego czasu (HASSLER 2020 [2018]) synonimizowana ze S. apetala Ucria; na temat sensowności tej synonimizacji por. np. MorTON (1972), patrz też skąpa diagnoza u UCRIA (1793). Ponadto, u HASSLERA (2020, „Catalogue of Life”), a prawdopodobnie za tym źródłem w wielu publikacjach internetowych, użyto nieprawidłowego cytowania nazwiska autora, Bernardino da Ucria: „Bernardino” zamiast „Ucria” (STAFLEU \& COWAN 1986: 562); to pierwsze używane 
jest w niektórych źródłach (MeikLe 1980 za IPNI 2020; BRummitT \& Powell 1992: 61) dla zakonnika z Bolonii (fra Bernardino da Bologna), znanego jedynie jako twórca zielnika z ok. 1773 r. (por. SACCARDO 1895: 28), brak jednak przesłanek do utożsamiania go z żyjącym w tym samym czasie (1739-1793) sycylijskim franciszkaninem, kuratorem ogrodu botanicznego w Palermo (por. SACCARDo 1895: 61, BRUMmitT \& Powell 1992: 659).

Główne cechy odróżniające Stellaria pallida od pozostałych przedstawicieli grupy to: jasno- lub żółtozielone zabarwienie pędów, szczątkowe lub niewykształcające się płatki korony, pręciki w liczbie 1-3 z najczęściej fioletowo zabarwionymi pylnikami oraz nasiona o średnicy wyraźnie poniżej $1 \mathrm{~mm}$ (np. RANDALl 1998; RotHMALER i in. 2005; TOWPASZ 1981, 1992). Rozmieszczenie gatunku w Polsce i jego charakterystykę fitosocjologiczną przedstawiła Popiela (1997). Mapa z tej pracy została zamieszczona następnie w atlasie ZAJĄCA i ZAJĄC (2001: 539) w wersji nieco uzupełnionej i uproszczonej.

Stellaria pallida uważana jest u nas za rodzimy składnik flory, zajmujący siedliska suche w lasach, na zboczach i w miejscach piaszczystych (TowPASz 1992), rozprzestrzeniający się także na siedliskach synantropijnych, często o charakterze ruderalnym, a w miastach najczęściej na trawnikach (por. np. Randall 1998; Atha i in. 2018; SNOwARSKI 2002-2020). Jest rośliną roczną lub hapaksantyczną, o szczycie rozwoju w okresie wiosennym. Pod koniec maja rozsiewa się, kończy wegetację i jej odnalezienie jest praktycznie niemożliwe (z tego powodu jest zapewne często przeoczana). Ogólne rozmieszczenie określane jest jako niedokładnie poznane (zapewne w związku z częstym nieodróżnianiem gatunku od S. media), południowo- i środkowoeuropejsko-zachodnioazjatyckie (RoTHMALER i in. 2005), ze stanowiskami synantropijnymi w Ameryce Północnej (MORTON 1972; HARTMAN \& Rabeler 2012; SwEARINGen \& BARgeron 2016; Atha i in. 2018), Ameryce Południowej (RothMALER i in. 2005; GBIF 2019; POWO 2019), południowej części Afryki (POWO 2019), Chinach (Lu i in. 2001), Japonii (GBIF 2019), Australii (Miller \& WeST 2012) i Nowej Zelandii (GARNOCK-JONES 1981).

Gatunek preferuje umiarkowaną strefę klimatyczną z wyraźnymi wpływami oceanicznymi (Rothmaler i in. 2005). Zgodnie z tą charakterystyką, Stellaria pallida znana jest u nas głównie z zachodniej części kraju (przez Polskę przebiega zapewne wschodnia granica zasięgu uznawanego za naturalny). W Europie zajmuje natomiast całą zachodnią część kontynentu (od Szwecji i państw bałtyckich na północy, przez Europę środkową po państwa bałkańskie na południu - CHATER \& HEYwOOD 1993; GBIF 2019), przy czym najdalej na wschód wysunięte stanowiska podawane są z Estonii (JANKEVIČIENĖ i in. 1993) oraz, zapewne oderwane od głównego zasięgu, na południu Ukrainy (część stepowa w pobliżu Morza Czarnego i Krym - ProKudin 1987). W bazie Euro+Med (MARHOLd 2011) wymieniono jako miejsca (naturalnego lub przypuszczalnie naturalnego) występowania gatunku również północnoafrykańskie i zachodnioazjatyckie kraje basenów Mórz Śródziemnego i Czarnego. W bazie Plants of the World online (POWO 2019, pod nazwa S. apetala) dołączono do nich jeszcze kraje Azji Środkowej (po Uzbekistan), Płw. Arabskiego oraz północną część europejskiej Rosji. PoPIELA (1997) jako najdalej na wschód wysunięte stanowiska w Polsce (pomijając wątpliwą datę z Lublina z 1964 r.) cytuje dane z Pojezierza Mazurskiego z 1908 r., natomiast z okresu powojennego - z Gostynia k. Tychów (DF62, 1982 r.) i Zagórza k. Częstochowy (DE72, 1987 r.). Tak więc poniżej opisane stanowisko 
jest jak dotychczas położonym najdalej na wschód w naszym kraju, spośród pewnych stwierdzonych po $1908 \mathrm{r}$.

W latach 2019-2020, w kwietniu i maju, obserwowano wystąpienie Stellaria pallida na terenach Lotniczego Parku Kulturowego w dzielnicy XIV Czyżyny w Krakowie. Gatunek nie był dotychczas podawany z tego miasta i jego okolic (np. TRzcińsKA-TACIK 1979; DuBIEL 1989; ZAJĄC i in. 2006); nie odnaleziono również alegatów z tego regionu w największych krakowskich zielnikach - KRA i KRAM.

Położenie geograficzne stanowiska: $50^{\circ} 05,0^{\prime} \mathrm{N}, 19^{\circ} 59,3^{\prime} \mathrm{E}$, ok. $220 \mathrm{~m}$ n.p.m. W siatce kartogramu ATPOL (ZAJĄC 1978; VEREY 2017) kwadrat 10×10 km: EF60 (w siatce $2 \times 2 \mathrm{~km}$, używanej w pracy ZAJĄC i in. (2006): EF6010; w siatce $1 \times 1 \mathrm{~km}$ : EF6030). Roślina tworzy tu płaty o powierzchni od jednego do kilku $\mathrm{m}^{2}$ (w sumie ok. 1 ara), wyraźnie wyodrębniające się na tle murawy, dzięki wspomnianemu wyżej charakterystycznemu, jasnemu, żółtozielonemu zabarwieniu pędów (Ryc. 1). Gatunek zajmuje fragmenty ubogiej w gatunki (patrz spis florystyczny poniżej), podsiewanej niekiedy murawy o charakterze miejskiego trawnika, koszonej 2-3 razy do roku (w zależności od potrzeb, m.in. organizowanych imprez). Przylega ona do pasa startowego fragmentu byłego lotniska Kraków-Czyżyny, obecnie pozostającego w zarządzie Muzeum Lotnictwa Polskiego jako park kulturowy. Jest to teren spacerowo-rekreacyjny, przy czym w ostatnich kilkunastu latach kilka razy do roku mają tu miejsce imprezy masowe (koncerty, Małopolski Piknik Lotniczy), w czasie których



Ryc. 1. Jeden z płatów Stellaria pallida na nowym stanowisku w Krakowie-Czyżynach

Fig. 1. One of the patches of Stellaria pallida at the new locality in Kraków-Czyżyny 
na murawie instalowane są stoiska, namioty lub lokalizowane są strefy dla widzów. Stąd też bardzo wysoce prawdopodobne jest, że roślina została na to stanowisko zawleczona. Być może jest ona w trakcie poszerzania swego areału na (południowy) wschód, do czego może wykorzystywać otwarte, zaburzane stanowiska synantropijne, ułatwiające jej konkurowanie z zadomowionymi gatunkami.

Syntetyczny spis florystyczny gatunków towarzyszących w płatach ze Stellaria pallida (gatunki dominujące wytłuszczono):

Achillea millefolium, Agrostis rubra, Capsella bursa-pastoris, Geranium pratense, Holcus lanatus, Hypericum perforatum, Knautia arvensis, Leontodon hispidus, Lolium multiflorum, L. perenne, Lotus corniculatus, Medicago lupulina, Plantago lanceolata, P. media, Poa pratensis, Potentilla repens, Prunella vulgaris, Ranunculus acer, $R$. repens, Taraxacum officinale, Trifolium pratense, T. repens, Vicia cracca.

Podziękowania. Publikacja powstała w ramach działalności statutowej Instytutu Botaniki im. W. Szafera Polskiej Akademii Nauk.

Summary. Stellaria pallida (Caryophyllaceae) - a new find for the flora of Kraków and the easternmost current station for Poland. A new locality of Stellaria pallida (Dumort.) Crép. was found in 2019 and still observed in 2020 in Kraków, southern Poland. The species grew on an extensively cultivated sward of the Culture Park of Aviation in the Czyżyny city quarter (Fig. 1). The presented station is the most eastern one found in Poland after 1908 (PoPIELA 1997) and may indicate range expansion in synanthropic habitats.

Stellaria pallida is sometimes synonymized with Stellaria apetala Ucria, although this may be doubtful - see eg. Morton (1972) and cf. scarce description in UCRIA (1793). Moreover, at HASSLER (2020; "Catalogue of Life"), and probably after this source at numerous Internet sites, for the latter taxon's author, Bernardino da UCRIA an erroneous citation was used: „Bernardino” instead of „Ucria” (STAFLEU \& CowAN 1986); the former is used in some sources (MEIKLE 1980 after IPNI 2020; BRUMMITT \& PowELL 1992: 61) for a monk, fra Bernardino da Bologna, known only as an author of herbarium from about 1773 (cf. SACCARDO 1895: 28), there are however no premises to identify him with his contemporary (1739-1793) minorite from Sicilia, curator of the Palermo botanical garden (cf. SACCARDo 1895: 61; BRUMMitT \& POWELl 1992: 659).

\section{LITERATURA}

Atha D., Wijesinghe D. P. \& Lazzeri V. 2018. First report of Stellaria pallida (Caryophyllaceae) for New York state. - Phytoneuron 2018-64: 1-8. http://www.phytoneuron.net/2018Phytoneuron/64PhytoNStellariapallidaNY.pdf (dostęp: 23.07.2020).

BRUmmitT R. K \& Powell C. E. (red.). 1992. Authors of plant names: A list of authors of scientific names of plants, with recommended standard forms of their names, including abbreviations. s. 737. Royal Botanic Gardens, Kew.

Chater A. O. \& Heywood V. H. 1993. Stellaria L. - W: T. G. Tutin, N. A. Burges, A. O. Chater, J. R. Edmondson, D. M. Moore, D. H. Valentine, S. M. Walters \& D. A. Webb, Flora Europaea (ed. 2). 1, s. 161-164. Cambridge University Press, Cambridge.

Dubiel E. 1989. Roślinność i flora doliny Wisły między Oświęcimiem a Sandomierzem. - Studia Ośrodka Dokumentacji Fizjograficznej 17: 137-208.

GaRnock-Jones P. J. 1981. Checklist of dicotyledons naturalised in New Zealand 8. Aizoaceae, Caryophyllaceae, and Portulacaceae. - New Zealand Journal of Botany 19: 59-65. 
GBIF [Global Biodiversity Information Facility]. 2019. Stellaria pallida (Dumort.) F.Crépin. - W: GBIF Secretariat. GBIF Backbone Taxonomy. Checklist dataset. https://doi.org/10.15468/39omei, https://www.gbif.org/species/5584066 (dostęp: 23.07.2020).

Hartman R. L. \& Rabeler R. K. 2012. Stellaria pallida. - W: Jepson Flora Project (red.), Jepson eFlora, https://ucjeps.berkeley.edu/eflora/eflora_display.php?tid=45501 (dostęp: 23.07.2020).

HassLer M. 2020 [wersja bazy datowana listopad 2018]. World Plants: Synonymic Checklists of the Vascular Plants of the World. - W: Y. Roskov, G. Ower, T. Orrell, D. Nicolson, N. Bailly, P. M. Kirk, T. Bourgoin, R. E. DeWalt, W. Decock, E. van Nieukerken \& L. Penev (red.), Species 2000 \& ITIS Catalogue of Life, 2020-06-04 Beta. Species 2000: Naturalis, Leiden, the Netherlands. www. catalogueoflife.org/col (dostęp: 22.07.2020).

IPNI 2020. International Plant Names Index. The Royal Botanic Gardens, Kew, Harvard University Herbaria \& Libraries and Australian National Botanic Gardens. https://www.ipni.org/a/710-1 (dostęp: 20.08.2020).

JANKeVIČIENĖ R., KuUSK V. \& Gavrilova G. 1993. XXXII. Caryophyllaceae A. L. Juss. 1. subfamilia Alsinoideae Vierh. - W: L. LAAsimer, V. KuUsk, L. TABAKA \& A. LeKavičIUs (red.), Flora of the Baltic countries. 1, s. 234-245. Estonian Academy of Sciences, Tartu.

Lu D., Wu Z., Zhou L., Chen S., Gilbert M. S., Lidén M., McNeill J., Morton J. K., Oxelman B., Rabeler R. K., Thulin M., Turland N. J. \& Wagner W. L. 2001. Caryophyllaceae A. L. Jussieu. - W: Flora of China Editorial Committee. Flora of China 6 (Caryophyllaceae through Lardizabalaceae), s. 512. Science Press \& Missouri Botanical Garden Press, Beijing \& St. Louis. - wersja internetowa: eFloras. 2008. Missouri Botanical Garden, St. Louis, MO \& Harvard University Herbaria, Cambridge, MA; http://www.efloras.org/florataxon.aspx?flora_id=2\&taxon_id=242000918 (dostęp: 20.08.2020).

MARHOLD K. 2011. Caryophyllaceae. - W: Euro+Med Plantbase - the information resource for EuroMediterranean plant diversity. http://ww2.bgbm.org/EuroPlusMed/PTaxonDetailOccurrence.asp?NameId=102480\&PTRefFk=7200000 (dostęp: 20.08.2020).

MeiKLE R. D. (red.). 1980. Draft index of author abbreviations compiled at the herbarium. s. 269. Royal Botanic Gardens, Kew. Her Majesty's Stationery Office, Reprographic Division, Basildon.

Miller C. H. \& WeSt J. G. 2012. A revision of the genus Stellaria (Caryophyllaceae) in Australia. - Journal of the Adelaide Botanic Gardens 25: 27-54.

Mirek Z., Pięroś-Mirkowa H., Zając A. \& Zając M. 2002. Flowering plants and pteridophytes of Poland. A checklist. - W: Z. MireK (red.), Biodiversity of Poland. 1, s. 442. W. Szafer Institute of Botany, Polish Academy of Sciences, Kraków.

Morton J. K. 1972. On the occurrence of Stellaria pallida in North America. - Torreya 99(2): 95-97.

PopIELA A. 1997. The distribution of Stellaria pallida (Caryophyllaceae) in Poland. - Fragmenta Floristica et Geobotanica 42(2): 355-360.

POWO 2019. Plants of the World online. Facilitated by the Royal Botanic Gardens, Kew. Published on the Internet http://www.plantsoftheworldonline.org/, http://powo.science.kew.org/taxon/urn:lsid:ipni. org:names:159051-1 (dostęp: 20.08.2020).

Prokudin J. N. (red.). 1987. Opredelitel' vysših rastenij Ukrainy. s. 548. Naukova Dumka, Kiev.

RANDAll R. D. 1998. Stellaria media / S. pallida / S. neglecta. - W: T. C. G. Rich \& A. C. Jermy (red.), Plant Crib 1998, s. 88-89. Botanical Society of the British Isles, London.

Rothmaler W., JäGER E. J. \& Werner K. 2005. Exkursionsflora von Deutschland. Band 4. Gefäßpflanzen: Kritischer Band. s. 980. Elsevier, München.

SACCARdo P. A. 1895. La botanica in Italia. s. 236. C. Ferrari, Venezia.

SNOwARSKI M. 2002-2020. Stellaria pallida Piré. - W: Flora Polski - atlas-roslin.pl. https://www.atlas-roslin.pl/gatunki/Stellaria_pallida.htm (dostęp: 19.08.2020). 
Stafleu F. A. \& Cowan R. S. 1986. Taxonomic literature: a selective guide to botanical publications and collections with dates, commentaries and types. $2^{\text {nd }}$ ed. 6 [Sti-Vuy]. s. 926. Bohn, Scheltema \& Holkema, Utrecht/Antwerpen, dr W. Junk b.v., Publishers, The Hague/Boston.

SweAringen J. \& BARgeron C. 2016. Invasive Plant Atlas of the United States. University of Georgia Center for Invasive Species and Ecosystem Health. http://www.invasiveplantatlas.org/subject. html?sub=3077 (dostęp: 20.08.2020).

TowPASz K. 1981. Stellaria neglecta Weihe w Polsce. - Zeszyty Naukowe Uniwersytetu Jagiellońskiego 566, Prace Botaniczne 8: 11-24 + 2 tab.

Towpasz K. 1992. Stellaria L., Gwiazdnica. - W: A. JAsiewicz (red.), Flora Polski. Rośliny naczyniowe. 3, s. 277-283. Instytut Botaniki im. W. Szafera, Polska Akademia Nauk, Kraków.

TRZCIŃSKA-TACIK H. 1979. Flora synantropijna Krakowa. - Rozprawy Habilitacyjne Uniwersytetu Jagiellońskiego 32: 1-278.

UCRIA B. DA, FRA 1793. Plantae ad Linnaeanum opus addendae et secundum Linnaei systema noviter descriptae. - W: Nuova raccolta di opuscoli di autori siciliani 6: 245-256. Solli, Palermo.

VEREY M. 2017. Teoretyczna analiza i praktyczne konsekwencje przyjęcia modelowej siatki ATPOL jako odwzorowania stożkowego definiującego konwersję współrzędnych płaskich na elipsoidę WGS 84. - Fragmenta Floristica et Geobotanica Polonica 24(2): 469-488.

ZAJĄC A. 1978. Założenia metodyczne „Atlasu rozmieszczenia roślin naczyniowych w Polsce”. - Wiadomości Botaniczne 22(3): 145-155.

ZAJĄC A. \& ZAJĄC M. (red.). 2001. Atlas rozmieszczenia roślin naczyniowych w Polsce. s. xii + 714. Nakładem Pracowni Chorologii Komputerowej Instytutu Botaniki Uniwersytetu Jagiellońskiego, Kraków.

Zając M., Zając A. \& ZemaneK B. (red.). 2006. Flora Cracoviensis Secunda (Atlas). s. xii + 291. Nakładem Pracowni Chorologii Komputerowej Instytutu Botaniki Uniwersytetu Jagiellońskiego, Kraków.

Wojciech Paul, Zakład Roślin Naczyniowych, Instytut Botaniki im. W. Szafera Polskiej Akademii Nauk, ul. Lubicz.46, 31-512 Kraków, Polska; e-mail: w.paul@botany.pl

Wptynęto: 20.08.2020 r.; przyjęto do druku: 16.12.2020 r.

DOI: https://doi.org/10.35535/ffgp-2020-0043

\title{
Stanowiska Nymphaea candida (Nymphaeaceae) oraz Nymphoides peltata (Menyanthaceae) w Kampinoskim Parku Narodowym
}

\author{
Kampinoski Park Narodowy wraz z otuliną otoczony jest ze wszystkich stron rzekami: od \\ wschodu i północy Wisłą, od zachodu Bzurą, a od południa Utratą, która jest dopływem \\ Bzury. Odcinek Wisły od Warszawy po Wyszogród jest szczególnie cennym obiektem \\ przyrodniczym i krajobrazowym. Właśnie to spowodowało, że w XX-leciu międzywo- \\ jennym powstał plan utworzenia w dolinie Wisły parku narodowego, którego inicjatorem \\ był między innymi Stefan Żeromski, a później Jadwiga i Roman Kobendzowie. Pomimo \\ że obecnie główny kompleks parku nie graniczy bezpośrednio z Wisłą, jego funkcjono- \\ wanie oraz geneza są nierozłącznie związane z tą rzeką (KAZIMIERSKI i in. 2003). \\ Wody powierzchniowe w głównym kompleksie parku zajmują obecnie 0,23\% powierzchni \\ całkowitej, co stanowi 10-krotnie mniej niż wynosi przeciętna krajowa (KAZIMIERSKI i in.
}

